\title{
VIDEOJUEGOS Y VIRTUALIDAD NARRATIVA
}

\author{
Francisco García García \\ Catedrático de Comunicación Audiovisual y Publicidad \\ de la Universidad Complutense de Madrid \\ fghenche@terra.es

\section{Resumen}

La presente investigación se pregunta por la narratividad de los videojuegos. Enmarca la pegunta en la forma de ser real, actual, virtual y potencial. Indaga en las formas de encuentro entre jugador, personaje y narrador. Y concluye que si bien todos los juegos no son narración, la construcción de la inmensa mayoría de los videojuegos remite a la narración; que lo más interesante no son los mundos que puedan compartir videojuegos y relatos, que lo más importante es la virtualidad que comparten; que no es el juego el que hace a los jugadores, sino los jugadores al juego; que la dialéctica creativa que el videojuego genera en relación con la historia que alimenta, contribuye a una teoría de la narratividad de los juegos; que la narración se inaugura, avanza y clausura por la acción del juego mismo y que el juego consiste en elegir.

\section{Palabras clave}

Videojuego, narración, real , virtual, actual, posible, real, jugadores

\section{Abstract}

The present investigation wonders for the narratividad of the video games. The pegunta frames in the way of being royal(real), current, virtual and potential. It(he,she) investigates in the forms of meeting between(among) player, personage and narrator. And he(she) concludes that though all the games are not a story, the construction of the immense majority of the video games sends to the story; that the most interesting thing they are not the worlds that could share video games and statements, that the most important thing is the virtuality that they share; that is not the game the one that does the players, but the players to the game; That the creative dialectics that the video game generates in relation with the history that feeds, contributes(pays) to a theory of the narratividad of the games; 
that the story inaugurates, it advances and closes for the action of the game itself and that the game consists of choosing.

\section{Keywords}

Video game, story, real, virtual, current, possible, players

\section{Introducción y objetivos}

Existe en estos momentos un gran interés por los videojuegos. Las razones son múltiples, unas de carácter epistemológico y teórico y otras, de carácter aplicado. En realidad las investigaciones frecuentan los dos campos y es más con frecuencia los interrelacionan. Nuestra investigación, como se podrá enseguida observar, se preocupa muy especialmente por una cuestión teórica, en ese sentido y por la misma metodología empleada se inscribiría en la epistemología, pero eso no obsta para que de sus conclusiones puedan extraerse aplicaciones prácticas. Indagar en la narratividad de los videojuegos desde la perspectiva de texto y juego en sí, de los jugadores, de los componentes narrativos, de las interrelaciones entre personaje, narrador, jugador y persona es plantearse cuestiones transcendentales en el campo de estudio que nos ocupa.

Nuestro objetivo viene espoleado por una pregunta que, de múltiples forma planteada, podría expresarse en alguna de ellas, como, por ejemplo, ¿existe narratividad en los videojuegos? Nuestra tarea en este momento es exploratoria, y por tanto vamos a dejar al lector con la duda de cuál es nuestra apuesta, aunque nuestra hipótesis de partida es favorable a su existencia. Los epígrafes siguientes hasta la conclusión final abren nuevas expectativas, nuevas preguntas y ofrecen diversos argumentos.

1.-Modos de ser en el mundo y videojuegos o las relaciones de potencialidad, realidad, virtualidad y actualidad.

Ahora sabemos que hay muchas formas de ser: el ser posible, el ser real, el ser virtual y el ser actual; que en lo más alto está el ser, el ser posible y el ser real; y que el ser real es virtual o actual. También 
sabemos que existen conexiones entre estos modos de ser, como sabemos que existen virtualidades posibles y actualidades posibles, y que para que algo sea actual antes debe ser virtual, ha de ser real y posible, porque en realidad lo actual no es sino la última elección de lo virtual y lo virtual una forma real de lo posible. Y que todo está en continuo devenir en el uso de las elecciones. Cada estado actualizado del ser, o clausura en sí su realidad o posibilita una nueva virtualidad.

El ser es ser en cuanto que ejerce la posibilidad de su realidad ya virtual ya actual. La riqueza del ser está en su virtualidad; su objetualidad, su ser uno por elección de entre lo múltiple, o sea, está en su actualidad.

El juego es virtual por las reglas que lo rigen, y actual, por las elecciones que ejercitan los actores. Pero una vez llevada a cabo una acción que consuma una elección, otra vez se abre un campo de posibilidades, independientemente del grado de dificultad; el jugador virtualiza, de nuevo en cuanto elige, nuevas opciones al problematizar esas posibilidades y ordenarlas en valor de oportunidad, y otra vez , de nuevo y constantemente, se le ofrece al jugador la acción de jugar, y con su elección actualiza el estado del juego en ese momento. Pero ese estado actual de realidad del juego solo dura mientras se ofrece al jugador una vez más la posibilidad de jugar o no jugar, y mientras éste decide ejercer la opción de jugar, virtualiza la posibilidad de jugar de esta u otra manera, y la manera que finalmente elige actualiza la jugada y da por resultado el estado actual del juego. Y así sucesivamente hasta que se consume la última acción del juego. Pero esa acción final, la acción resolutiva, no tiene por qué ser la consecuencia de agotar ni las posibilidades ni las virtualidades del juego en sí, sino que puede ser el resultado de una decisión del jugador de abandonar la partida, cortar de forma abrupta las posibilidades y las virtualidades del juego.

Pero, entonces qué es lo virtual. A contestar esta pregunta ha dedicado todo un libro Pierre Lévy (1999) Aunque no de forma definitiva, entre otras cosas, porque lo virtual también es real. Levy $(1999,25)$ aproxima un concepto. Las cosas sólo tienen límites claros en lo real (desde mi punto de vista sólo sería en lo real actual). La virtualización, pasaje a la problemática, desplazamiento del ser sobre la cuestión; necesariamente pone en tela de juicio la identidad clásica, pensada con la ayuda de definiciones, de determinaciones, de exclusiones, de inclusiones y de tercios excluídos. Es por esto que la virtualziación es siempre heterogénea, volverse otro, proceso de recepción de la alteridad. Es ese pasaje a la problemática lo que convierte a la realidad tanto en heterogénea, como en estar completamente en proceso de ser otra, de estar en el límite de la no definición definitiva. 
Ahora habríamos de preguntarnos cómo se relaciona ontológicamente lo virtual con los otros modos de ser, gracias a la realización, potenciación, actualización que se ejerce sobre ellos, y que atendiendo a los factores de orden, causalidad y temporalidad quedan trasformados .

Ya hemos dicho que son inconcebibles sin la conexión que los une entre sí, pero también habremos de separarlos en el espacio de la inteligencia para comprender clara y distintamente lo que son cada uno por si y en su relación con los otros.

Este cuadro tomado de Lévy nos los resume perfectamente.

Transformación Definición Orden Causalidad Temporalidad

$\begin{array}{llll}\text { Realización } & \text { Elección } & \text { Selección } & \text { Material } \\ & \text { Caída potencial } & & \end{array}$

\begin{tabular}{|c|c|c|c|}
\hline Potenciación & $\begin{array}{l}\text { Producción } \\
\text { de recursos }\end{array}$ & Selección & Formal \\
\hline
\end{tabular}

\begin{tabular}{llll}
\hline Actualización & $\begin{array}{l}\text { Resolución de } \\
\text { problemas }\end{array}$ &
\end{tabular}

Virtualización Invención de Creación Final Eternidad


problemas

Como ya se ha dicho antes lo virtual, y por ende la virtualización, se caracteriza por problematizar, por poner en juego su capacidad para definir los problemas, para percibir lo múltiple. Lo virtual es generador de orden y la causa por la que se mueve es la causa final, aquella causa que opera por la atracción del fin, y se mueve dentro de la eternidad. La actualización fija una solución dentro de los posibles y de las propuestas por la invención de los problemas en la transformación de la virtualización; es de naturaleza creativa y la causa por la que se actualiza es la eficiente, o sea aquella que nace de un agente y depende de una acción. La potenciación, o por lo que las cosas se hacen posibles, reconstituye los recursos, pone orden y se rige por la causa formal. Las estructuras y las formas existen. La realización, algo por lo que las cosas pierden su potencial diferencial, pero que gracias a la elección y la selección, fija el ser gracias al tipo de causa material en un orden de circunstancias concretas.

Lo posible y lo virtual tienen en común su calidad de ser latentes y no manifiestos, mientras que lo real y lo actual son manifiestos. Según Pierre Lévy, la forma de ser de lo posible es que insiste; lo real, subsiste; lo virtual, existe y lo actual llega.

Entre el sujeto y el mundo, entre el jugador y el mundo del juego, existen muchas formas de mediación. La mediación, entre otras, de los sentidos y la mediación de la inteligencia. Como ha dicho Philippe Quéau $(1995,23)$ las imágenes permiten la percepción sensible de modelos inteligibles. Un modelo es una concepción formal, anotada con símbolos lógico-matemáticos y memorizada en forma de programa informático. La imagen propone una representación visible y el modelo una representación inteligible. Entre los dos cabe una relación cooperativa de tal forma que la imagen pueda ayudar a comprender el modelo mismo gracias a la representación sensible. Las representaciones virtuales están ligadas a los números, mientras que las técnicas analógicas de representación lo están ligadas en primera instancia al mimetismo con lo real, a través de las representaciones fotográficas, cinematográficas o radiofónicas, visuales o auditivas. Ahora bien la digitalización nos permite reducir todo a una misma materia y desde ahí todo es posible, todas las recombinaciones son factibles como ha dicho Nicolás Negroponte, porque la naturaleza de todas las sustancias expresivas (imágenes, palabras, sonidos, música...) ya todas son digitales. Los videojuegos se valen de estas técnicas y permiten la percepción sensible de las imágenes en los modelos 
inteligibles de puesta en escena de las virtualidades actualizadas por la forma de hacer del juego, por la elección.

\section{2.-El videojuego como juego o el arte de participar}

Convendría recordar que el videojuego es ante todo un juego y que a lo largo de la historia y hoy mismo el concepto de juego ha interesado a los grandes pensadores, a los sociólogos, a los psicólogos, a los educadores, a los antropólogos, a los comunicadores... y a los productores de la industria del espectáculo y de la cultura. Así Spencer justificaba la existencia del juego como la expresión de un impulso biológico, capaz de liberar la energía sobrante de los seres humanos. Más tarde Schiller hablaría también de impulso, en este caso, artístico dotado del don de la gratuidad y de la gracia. Wunt aporta a la teoría del juego una visión original que consiste en el concepto de heterogénesis, según el cual los juegos expresarían una gran distancia entre el origen donde se inspiran y la finalidad que quieren conseguir. El juego es juego y no obligación, está exento de las responsabilidades de las acciones humanas a las que pudiera imitar. El sentido del juego se orienta a servir de preparación para la vida como defiende Groos. Huizinga ha sido uno de los investigadores que ha hecho mayores aportaciones a las teorías del juego. No hay juego sin libertad, ni independencia, gracias a lo cual el jugador al elegir el juego en que mejor se representa genera cultura y produce una transformación de lo real. Fink eleva el rango del concepto del juego, desde una perspectiva filosófica, definiéndolo como la libertad para alcanzar la individuación humana dentro del cosmos. Pero eso se logra dejando ser, como diría Heidegger. Leibiniz, uno de los grandes pensadores, dignifica este concepto cuando dice que mientras Dios juega se hace el mundo, pero al mismo tiempo le concede al juego un gran valor de creación. Gadamer incide en el carácter dialógico del juego, eso que ahora entre otras cosas llamamos interactividad. Se activa el juego en el horizonte del diálogo. Esa capacidad del juego para el diálogo es tan grande, que se constituye en su carácter y naturaleza. No son los jugadores lo que hacen posible el juego sino al revés. Ni siquiera son las reglas las que hacen el juego, sino al contrario. Todos los juegos se parecen en algo, tienen un aire de familia en palabras de Wittgenstein . Pascal cree en la constitución azarosa del juego. Las reglas nacen como una forma de pacto entre el azar y la necesidad. El azar ignora el fin, la necesidad lo determina, y la estrategia lo busca. Neumann y Morgenstein piensan en el juego como estrategia, cómo desenvolverse en un ambiente dado, cómo orientar las acciones a los fines. La teoría de los juegos, la ciencia de los conflictos y la lógica formalizada con su teoría de las reglas 
formalizadas y formalizables por situación abren una nueva expectativa al concepto de juego a la que se une el concepto de las intenciones subjetivas de Richard M. Martín.

En estos momentos las aportaciones de las Nuevas Tecnologías y las experiencias de jugadores, más concretamente de los videojugadores, como jugadores y como sujetos nos hacen querer saber más. Desde el punto de vista teórico y epistemológico una de las preguntas más interesante es la narratividad del videojuego. Parafraseando a Leibniz, cum Deus calculat, fecit mundus, mientras el jugador juega se hace el mundo, se construye la narración en el juego. ¿En qué medida y en qué tipos de juegos, jugar es narrar; y en qué medida y en qué tipo de narración, narrar es jugar?

Roger Cailloix (1961) citado por Marie-Laure Ryan (2004, 221) distingue cuatro tipos de juegos basados en la naturaleza misma del juego y no en la temática del juego.

Agon. Son los juegos de competición, ya sean individuales o colectivos, ya entre uno o varios jugadores, como son los deportes, los juegos de mesa o los concursos de televisión o radio. Alea. Son los juegos de azar. Desde el dominó a cualquiera de los juegos de cartas o algunos de los juegos de mesa. La suerte está echada. Pero la suerte también ayuda a los mejores. De ahí que existan jugadores expertos que saben jugar con cualquier baraja y saben sacarle el mayor rendimiento a lo que el azar le depara. Mimicry o juegos de imitación, los juegos del como sí. Ilinx. Se trata del uso de la transgresión de los límites, caos, metamorfosis, inversión de las reglas. Cailloix (1961) dice que son esos juegos en los que lo esencial es perseguir el vértigo y que consisten en un intento de destruir momentáneamente la estabilidad de la percepción o en introducir una especie de pánico voluptuoso en una mente habitualmente lúcida. Se tratarían más bien de rituales de iniciación, experimentación con drogas... Echo de menos con Marie-Laure Ryan (2004) los juegos de construcción y los uniremos a una clasificación final.

Cualquiera de estas categorías de Cailloix, incluida la de los juegos de construcción, es aplicable a los videojuegos. En el estado actual del desarrollo de los videojuegos, parece indudable que es la primera, la de agon, con ese concepto de lucha, la que se impone en los videojuegos. También pudiera parecer que es la que menos juego da en el estudio de las relaciones entre juego y narración, en general, y videojuego y narración en particular. Los creadores de videojuegos de este tipo, centran su atención, más que en organizar 
estructuras ricas y complejas, en la habilidad de un tipo de gestos motores, psicomotores o cognitivos ordenados a ganar; y ganar es derrotar a los enemigos. Sin embargo mientras juegas, se crea la narración (cum Deus calculat, fecit mundus) El mismo juego instaura un relato, ya sea en tercera o primera persona. El fin del juego pudiera corresponderse con el proyecto narrativo, la causa final por la que se mueven los personajes. Otra cuestión bien distinta es la complejidad del juego y de la narración. Por muy elemental que sea la suerte del jugador en cuanto jugador, en cuanto construye texto, le interesa al sujeto del juego, a la persona que juega. El videojuego es un texto, y esto lo distingue definitivamente de otro tipo de juego.

El videojuego narra el devenir del juego al jugarse, textualiza el propósito, el origen y el punto de partida, las reglas, los jugadores y la suerte que corren a través de sus acciones para conseguir sus objetivos, las secuencias y las relaciones de continuidad entre las partes, entre los efectos y las causas y entre la implicaciones estructurales. Al narrar el juego, el jugador es ya el personaje. En la acción de jugar se crea el relato, y éste avanzará según el diseño del juego, pero dado el carácter textual del videojuego narra, textualiza por el mero hecho de jugar. Así es como el jugador se convierte en personaje. El juego finaliza cuando el jugador gana y podrá volver a jugar y jugar, pero el placer consiste en superar un grado de dificultad y si es mayor dificultad, mejor. En cambio la lectura de un texto es inagotable, y volver a leer descubre nuevas lecturas y proporciona nuevo placer.

Sin embargo, muy especialmente en los videojuegos de origen histórico, el jugador ya es un personaje, dicho de otro modo, la modelización del jugador y su caracterización se inspiran en un personaje. Las reglas del juego también se inspiran en un modelo de narración y en un modelo de mundo previo. Pero el jugador-personaje con el que yo jugador-lector me identifico, y a cuya caracterización y reglas de juego me someto cuando juego, crea su propio devenir al actuar según las reglas dadas en un mundo modelo previamente definido. Si bien sé cuál es mi objetivo, o sea, ganar; si bien conozco en qué consiste y cómo se logra ganar, lo que no sé es si lograré ganar, si tendré la habilidad suficiente o si terminaré el juego cualquiera sea la causa por la que dejo de jugar. Si el juego consiste en ganar a la máquina, al constructo textual contra el que juego y que responde a mis decisiones, según unas reglas y unas previsiones fijas y predeterminadas por el autor del videojuego; si contra el que juego es contra otro u otros jugadores con las reglas definidas y con finales más o menos abiertos, eso es cuestión de grado, de implicación y de las relaciones entre los jugadores, lo importante es que mientras juego, mientras jugamos instauramos el mundo 
del relato por muy rudimentario que éste pueda ser, y que el mundo del relato y el mundo del juego por encima de sus enormes diferencias comparten tres tipos de instancias, el yo que juega, el sujeto de carne y hueso que subyace a la actividad del juego; el jugador en sí y cuya esencia consiste en que juega, un sujeto cualquiera virtualmente jugador que actualiza su cualidad de jugador en el mismo acto de jugar, y cesa con él; y un personaje, que como instancia narrativa es diferente al sujeto que juega y al jugador. Es más con el cese del juego, y con su aniquilación, cesa la narración, también. Cuando el juego se pone a cero, también se pone la narración. Pero ambos debido a la persistencia en el soporte informático del texto del videojuego, permanecen virtualmente. Cuando el jugador active el sistema, y las reglas se pongan en juego, al actualizar el jugador sus elecciones, el relato en estado virtual actualizará también su mundo narrativo.

Si los juegos de agon se caracterizan por la definición y articulación de las estructuras y las reglas del juego, en el extremo opuesto se sitúan los ilinx. Es el terreno del juego libre, el mundo de la imaginación, la ausencia de reglas. Bajtin lo asocia con lo carnavalesco, como recoge en forma de cita indirecta libre Marie-Laure Ryan (2004):

Las estructuras caóticas, la anarquía creativa, la parodia, el absurdo, la heteroglosia, la invención de palabras, la subversión de los significados convencionales(...) los desplazamientos de las figuras, los juegos de palabras, el desbaratamiento de la sintaxis, la melánge des genres, las citas equivocadas, las mascaradas, la transgresión de las barreras ontológicas (imágenes que cobran vida, personajes que interactúan con su autor), el tratamiento de la identidad como una imagen plural, cambiante... En resumen, La desestabilización de todas las estructuras, incluidas las que crea el propio texto. Este tipo de juegos aunque es posible que tengan su gran momento en el futuro, hoy no dan razón de lo que son los videojuegos en sí. En gran medida se debe a que están muy dominados por un conjunto de reglas fijas que proporcionan la forma en que el jugador participa en el juego, activando una opción sobre las demás. Ciertamente lo juegos se basan en las reglas, y éstas lo constituyen, pero ya hemos dicho más arriba que hay juegos que pueden autogenerar sus propias reglas en el acto mismo de jugar. Lo que nos interesa en gran medida es también el acto creador del juego.

Los juegos basados en el azar han tenido una gran importancia en lo que podría llamarse una historia general del juego. El azar es un elemento esencial en la configuración de los juegos, y muchos de los juegos de ordenador se basan en el azar. Sin embargo es la dialéctica entre azar y necesidad a mi modo de ver lo 
que define a los juegos. Los sucesos aleatorios no serían nada para los hombres ni en la vida ni en el juego. Sólo si estamos cautivados por el fin, por el objetivo definitivo por el que nos movemos, podemos actuar en una dirección ayudados por las reglas sociales o del juego, alertas para interpretar los espacios del azar.

Es en los ámbitos de las opciones facilitados por las leyes y las reglas donde se puede ejercer la libertad, y desde ahí jugar, sólo juega el que tiene la posibilidad de elegir una opción entre varias, sólo es libre el que es capaz de percibir las alternativas y optar por una. El movimiento OULIPO y el propio Italo Calvino, uno de sus miembros marginal más significado, se debaten entre el azar y la combinatoria. Italo Calvino llega a definir la literatura como un juego combinatorio que juega con las posibilidades intrínsecas del propio material. La tentación combinatoria aplicada a la literatura ha estado presente en muchas de las experimentaciones de la técnica surrealista de la escritura automática, ha azuzado la práctica de generar textos por ordenador mediante la selección aleatoria y la combinación de palabras de una base de datos. En este sentido, los juegos de ordenador han explotado las posibilidades de los juegos basados en el azar como componente determinante. Pero no, al menos en esa medida, en los videojuegos.

Los juegos de imitación son de capital importancia para las relaciones entre juego y narración. Pudiera ser que el mundo que pretenden imitar estos tipos de juego fuera la referencia de mundo que sirve de estructura base para los creadores del juego y muy especialmente para el desarrollo del juegos por parte de los jugadores. Obviamente este tipo de juego puede estar temática y estructuralmente inspirados en avatares de la realidad, en acontecimientos actuales o históricos, en modelos de conducirse continuamente o también en modelos de mundo ficcionales.

La comparación entre juegos de hacer como sí y ficción no es nueva, según Marie-Laure Ryan (2004, 134) se encuentra ya implícita en la definición, proporcionada por Coleridge, de la actitud de los lectores de poesía como suspensión voluntaria de la incredulidad $(1975,169)$ y ha sido objeto de estudio por otros autores como Susanne K. Lannger, Walton o Jhon Searle (que decía que se trataba de un acto lingüístico aparente)

Walton (1990) infiere un conjunto de reglas a partir del análisis que hace de los juegos de como si, según la cita de Marie-Laure Ryan $(2004,135)$ 
a) Los jugadores escogen un objeto real $x$-el instrumento- $y$ se ponen de acuerdo para hacer como si se tratara del objeto virtual $x 2$

b) Los jugadores se imaginan a sí mismos como miembros del mundo virtual en el que x2 es real, las acciones que los jugadores realicen con el instrumento cuentan como acciones realizadas con $x 2$

c) Una acción es legal cuando el comportamiento que conlleva es apropiado para el tipo de objeto representado por x2. Una acción legal genera una verdad de ficción. Dicho de otra manera, una verdad de ficción es una proposición que es real en un juego de como sí.

Una de las consecuencias más importantes de este tipo de juegos es la alta implicación de los jugadores, la forma en que se comporten las características de mundo entre el relato y el juego. Cada vez que el jugador juega y cuanto más juega, más se fortalecen las relaciones entre el mundo de referencia y el instaurado en el juego del como si.

Los dos tipos de juegos que más han modelos ha aportado a los videojuegos son el agon y los juegos de imitación. Sin embargo hay otro tipo que puede en el futuro tener mucho éxito, es el juego de composición o construcción, en sus más variadas manifestaciones. Ya se reduzca sólo a juegos de ordenador o dé el salto a videojuegos, los juegos de composición presentan una foto fija final, que los jugadores partiendo de las posiciones en que se encuentren en el momento inicial del juego intentan conseguir componer, resolviendo diversos enigmas y superando las más diversas pruebas.

Pero ésta es sólo una de las formas de entender los juegos de composición o construcción, otra es la de aquellos juegos que se van dando sus propias reglas. Así, si el texto genera sus propias reglas, el lector, el jugador se encuentra obligado a desentrañar el código del juego a medida que juega. Aquí la actividad creativa del jugador es máxima.

Por último, hay que añadir a los juegos de agon, azar, de imitación o como sí, a los de juego libre y a los de composición, otro tipo de juegos de modelo complejo y que integra características de más de un modelo de juego, serían los juegos mixtos. 


\section{3.-El proceso creativo del videojuego o el eje de articulación narrativa entre lo virtual y lo actual.}

Cuando el jugador interviene en el juego el relato se modifica en tiempo real ante los ojos mismos del lector, del jugador contrario que ve su posición modificada con sólo la intervención en el juego de su antagonista. El juego escribe su propia historia que constantemente se ve modificada por cada jugador. Existe la historia del juego en sí mismo y la historia que el juego ejecuta como contenido. A veces coinciden como coincide el devenir del jugador con el autor y el personaje. A veces sólo el autor actualizante del juego y el jugador en cuanto jugador coinciden. Pero hay un autor anterior a todos, el primer autor, el autor generador de la estructura del juego donde todas las historias de este juego son posibles, y siendo posibles serán virtuales y, si virtuales, factuales.

El autor de la matriz del juego es sólo el autor del juego posible y virtual. Sólo el jugador en cuanto que juega hará posible que el juego sea real y actual. No hay juego posible hasta que no se juega. No hay relato hasta que la historia no se narra. Pero aún así todavía no hay texto ni relato posible. Sólo cuando se lee, ha nacido el texto. Por la misma razón no habrá historia si el juego no se vuelve texto, y no habrá texto mientras no haya lectura, y leer el juego es jugar, y jugar es activar tu jugada. Lo que vemos es que la historia no avanza si no juegan los jugadores. No basta que uno juegue, el juego es interacción entre dos jugadores que se encuentran entre sí sólo porque responden con una jugada cada vez que les toca. Pero la creación de la historia sólo se ejecuta entre dos y el discurso es resultado del efecto de la interactividad de cada jugador con la historia en sí, y sólo se hace conocer por el discurso interactivo al otro jugador. Los jugadores en el videojuego nunca hablan entre sí, nunca interactúan, su forma de relación es mediada con el texto interactivo, se relacionan en cuanto que activan los resortes virtualmente interactivos del videojuego en cuanto texto jugado. Cuando los jugadores interactúan entre sí no lo hacen como jugadores, sino como personas; su relación no es intratextual, sino extratextual.

\section{4.-El acto de jugar o las relaciones virtuales entre lo uno y lo múltiple.}

La realización entre lo virtual y lo actual es de uno-a-muchos (one-to-many, según M-L. Ryan, 2004) Sólo es posible una actualización del número posible e indefinido de virtualizaciones. Jugar es elegir. 
Pero la elección es irreversible, no se puede volver a atrás, no se puede deshacer lo hecho. En el mismo momento en que se ha elegido, ya se ha establecido un nuevo ámbito para el luego, para el otro jugador, ya ha emergido una nueva realidad donde florecen nuevas alternativas, virtualidades vivas, que esperan su momento en el altar de las decisiones de los jugadores. Quien mueve una pieza en el ajedrez, no sólo ha cambiado de posición esa pieza en el tablero, sino que ha ofrecido un nuevo ámbito de realidad, ha reorganizado las fuerzas de las figuras en mayor o menor profundidad. Cuando mueva el siguiente jugador habrá de calibrar los cambios que ha introducido ese movimiento. Y aunque pueda mover cualquier ficha habrá de calibrar la opción que mejor pueda ayudar al objetivo final del juego. Sobre el tablero está el panorama virtual, la nueva jugada lo convertirá en un instante en actual, pero cuando el jugador contrario tenga la acción de jugar, ya habrá sobre el campo de juego una nueva virtualidad, o conjunto de virtualidades donde ejercer a través de lo posible el acto. Pero quien mueve no sólo piensa en el resultado de su acción inmediata por lo que actualiza el estado del juego, sino que piensa en cuantas posibilidades de virtualizar el juego tiene, y también en su próxima jugada, y en la jugada del contrario y así hasta dónde puede llegar su inteligencia de organizar alternativas en un campo de batalla simbólico, como es el ajedrez. Simbólico y narrativo. La suerte final del rey es la suerte del jugador, y la suerte del jugador es la suerte de la persona. No muere el rey, muere el jugador; no pierde el jugador, pierde el yo que juega; y así simbólicamente muere el yo que juega al perder la partida.

El autor del juego, tal como se hace hoy jugando, es el yo que juega. Dicho así el jugador es el autor de la narración en cuanto activa los resortes del juego. El juego es la historia que se inventa en el acto de jugar bajo unas condiciones, espacio, tiempo, personajes y es también indiciario de acciones de salida, y a través de unas reglas dadas.

Lo significativo y diferencial de los videojuegos, en cuanto que aun, por precarios que sean, son narraciones, es que el jugador puede ser, a la vez, autor de la narración, personaje de la misma y jugador del juego, en este caso estaríamos ante un videojuego homodiegético. En el caso de que no hubiera coincidencia entre el jugador y el autor actualizante con uno de los personajes del videojuego se trataría de un videojuego heterodiegético. 
Cada jugador actualiza su situación de autor y lector con el momento de su intervención en el juego. Y su posición es cruzada respecto al otro jugador. Cada uno es especular respecto a su contrario. Cuando un jugador juega, actualiza la historia y el estado del juego como jugador y es autor de la narración; mientras el otro, es espectador y lector de esa actualización del juego. Siempre cambiantes sus posiciones siempre en situación especular respecto al contrario, siempre lectores o autores, siempre actualizadores o virtualizadores. Juego y narración. El jugador inventa, virtualiza y actualiza la historia que va a jugar y espera la invención, virtualización y actualización del jugador contrario. Jugar es estar pendiente de la jugada de la vida, siempre por hacer hasta que se clausura definitivamente.

La comunicación cibernética instaura un nuevo modo de ser que es verdad que nace del juego, pero que le ofrece una nueva posibilidad del one to many, del uno a muchos se pasa del many to one, del muchos a uno. Pero la acción de reciprocidad sólo será posible en cuanto esos muchos se individualicen en un colectivo o ese many sea la conjunción de todos los one, tomados de uno en uno. La comunicación de masas, la publicidad, el marketing habían seleccionado una vía, la del uno a muchos, pero ahora cada uno de esos muchos exige su parcela de elegir a uno o a varios pero como uno, o incluso a varios, pero de uno en uno. La comunicación interpersonal que activan los juegos multijugador, en que uno juega contra todos, al mismo tiempo que lúdicamente juega contra cada uno del conjunto “todos”, y cada uno de ese conjunto juega contra él y contra todos tomados de uno en uno. Quien entra en un chat puede hablar con todos o con un conjunto de ese todos en que se articula la sala principal del chat en perfiles determinados, pero en realidad podrá hablar con todos, pero no es el “todos” el que tiene identidad personal, ni un grupo reducido, quien habla por si o por el grupo, es siempre un individuo.

\section{5.-El placer de jugar y de contar o la inmersión y la interactividad en el juego y la ficción}

Meterse dentro del juego o del relato, o del juego y el relato al mismo tiempo, en el caso en que la acción del juego genera una narración; olvidarse del mundo que habitamos para penetrar el mundo del juego o de la ficción; vivir la vida que otros vivieron, en palabras de Miguel de Unamuno, como propia; suspender nuestra incredulidad, como diría Coleridge; crear imágenes en la memoria que producen sensaciones más allá de la realidad de los acontecimientos del juego o el relato; es sentirse absorbido por el juego o por la ficción. La inmersión exige, al menos inicialmente, ciertas actitudes y actividades del sujeto. Existen juegos 
y relatos de ficción que exigen, dadas las dificultades de iniciación de mundo o de compresión de reglas o de habilidades lúdicas o discursivas, una gran atención del jugador o del lector, pero una vez metido en el juego o en la historia comparte el universo, se produce la inmersión.

La inmersión se relaciona con el tiempo, el jugador se pierde en el texto o en el juego por cierto tiempo, y se distingue de la adicción, que busca tanto escapar de la realidad como perderse en la ficción sin capacidad para distinguir el mundo de la realidad como el mundo de la ficción. La inmersión es otra cosa, es más que una implicación con el texto, es alcanzar una experiencia inmersiva, aunque haya grados, en que sabiendo que una cosa es la ficción y otra la realidad, te absorbe por completo y entras en el mundo de la representación -juego/ficción, de tal forma que desaparece el medio mismo (realidad virtual, texto, etc.) y el acto de leer y/o de jugar, y estás viviendo la situación como parte de la misma.

Cuáles sean las características de los juegos y cuáles, las de los mundos compartidos de la ficción, y cuál sea también la disposición del lector y el jugador influirán profundamente en el grado de inmersión y en el placer que le produzca. Es más que imaginarse la situación, es simular mentalmente las situaciones, las acciones, los jugadores o los personajes, y muy especialmente, imaginarse a uno mismo, lector y jugador como parte de ese juego en una situación imaginaria o lúdica concreta. Del hacer como si, al yo como sí. El mismo Aristóteles deparó en ello al hablar de cómo había que estructurar las fábulas: Poniéndolas ante los propios ojos lo más vivamente posible; pues así viéndolas con la mayor claridad, como si presenciara directamente los hechos...

Las Tecnologías de la Información y la Comunicación han proporcionado a los videojuegos unas herramientas de gran alcance orientadas muy especialmente a la inmersión y a la interactividad, que no hay que olvidar nunca que no son más que una dimensión de la interacción del cara a cara entre los humanos. Es más, inmersión e interactividad en los videojuegos se alían para conseguir sus objetivos. Las tecnologías han permitido a los jugadores enfrentarse a la máquina como a un rival, no son pues, necesarios otros jugadores humanos. Frente al jugador de videojuegos siempre habrá otro jugador, pero este es posible que sólo sea una máquina que activa determinadas respuestas a las preguntas que las propias respuestas del jugador han dado a su última jugada. Ahora bien, el ordenador pone en juego un programa que tiene previstas todas las opciones posibles para contestar al imput que envía el jugador humano. 
Cuando se dan juntas interactividad e inmersión, el placer es superior. Y todavía lo será más cuando el jugador se olvide de la autoreflexibilidad, o sea, pierda la conciencia de que está jugando y que lo está haciendo frente a un programa de ordenador. Los avances científicos que buscan la invisibilidad de la tecnología y de la transparencia del medio, por una parte, y la actitud del jugador, por otra, son dos elementos claves entre otros para una, cada vez, más profunda y placentera experiencia inmersiva.

No basta con una actitud conversacional o de participación por parte del lector para que se pueda dar la interactividad, es preciso disponer de un medio interactivo, y el ordenador lo es, y de un texto o un programa informático interactivo. Y un texto interactivo hace uso de las aportaciones del lector, gracias a las cuáles puede activar determinadas respuestas, e incluso promover algunas preguntas.

Marie-Laure Ryan (2004, 250) propone ocho tipos de textos interactivos, tomando como referencia, la teoría de Aarsperth (1999, 31-44) de diseño ergódico (ergon y holos, que significan “obra” y “camino”), añadiéndole los caracteres de textos electrónicos e interactividad, y combinando la presencia o ausencia de algunos de estos elementos. Aasperth define a la literatura ergódica como aquella obra en que el lector necesita aportar un cierto esfuerzo para atravesar la obra. Sólo es interesante para nuestro objetivo los textos definidos como ergódicos, electrónicos e interactivos. O sea aquellos que precisan cierto esfuerzo para ser atravesados, ya sea a través de pruebas que hay que resolver, dificultades para la comprensión de los textos o de las reglas del juego, o de las habilidades cognitivas, psicomotoras o cualquier otras; que su lectura o juego precise de medios electrónicos y en nuestro caso informáticos; y por último, que pongan en juego las propiedades interactivas de los juegos y los textos, y la actitud del jugador o lector para establecer ya sea interactividad con el texto, ya de interactuar con otros jugadores a través del medio informático.

El lector puede alcanzar interactividad con el texto por muchas razones y para muchas finalidades (recuperar información, evaluar textos, cooperar en la producción textual con otros autores, ampliar pantallas, sugerir relaciones textuales, acceder a bancos de datos, resolver problemas, cambiar perspectivas, explorar posibilidades, generar y activar enlaces, producir hipertextualidad...) y puede establecer relaciones de interacción a través del juego o del texto con otros lectores y otros jugadores, y establecer de una forma 
más directa interacciones entre los participantes de una conversación, por ejemplo. Y naturalmente lo puede hacer en tiempo real.

El jugador de videojuegos cada vez más dispone de recursos de extraordinario valor para jugar y ganar. Su interés no es por tanto intercambiar información, excepto la imprescindible para conocer las reglas del juego, ni tampoco establecer relaciones personales con otros jugadores, excepto las que exige el juego. El objetivo del jugador es jugar, y eso, si mientras, juega se hace el mundo. Un mundo ya previamente establecido o ya mundo que nace del acto de jugar. Y ese mundo es inevitablemente compartido por los jugadores, si es previo al inicio del juego y sobre el que el juego fundamenta sus reglas, como sucede en los juegos de como si, previamente será conocido por los jugadores, pero si fuera el resultado de la emergencia de la actividad del juego todos los jugadores estarían construyendo el mundo con sus jugadas y la forma de compartir el mundo, sería también la forma de hacer el mundo cooperativamente en cada tirada, en cada participación, en cada jugada.

\section{6.-El videojuego como texto construido o el encuentro de las instancias lúdicas y narrativas.}

El juego es un texto, y el texto, un objeto virtual, cualquiera sea el soporte donde se manifieste. El texto necesita la acción de un lector para actualizar su virtualidad. Por la acción de leer el texto, el elector ejercita una opción, la separa del resto, la problematiza, recorre sus posibles soluciones y decide una. Ha leído. Ha comprendido. Ha archivado en su memoria. No sólo le será útil para su conocimiento, para ampliar su saber, sino como archivo que podrá ejercer su memoria y actualizar esos memex para actualizar nuevos fragmentos del texto, interpretar es relacionar, relacionar es proponer nuevas alternativas, virtualizar las opciones de lectura para que el lector actualice el sentido final, aunque no necesariamente el final definitivo. Mientras se lee, mientras hay lectura sobre la actualización clausurada en el último sentido o en los sentidos parciales impera la virtualidad, pero no se ha ejercitado la última voluntad, la decisión clausuradora del sentido.

Como ya hemos dicho, el juego es una narración. Las personas, los sujetos individuales o colectivos son sujetos del mundo real, actual, presenciales en una realidad dada. Van a ejercer una conversación mediada, han convenido relacionarse a través de un juego, y como tales ejercen ese modo de relación. Su 
función es jugar y ganar, se comprometen a respetar las reglas del juego. Su acción y su compromiso pragmático consisten en comportarse como jugadores que respetan unas reglas, y que creen que los otros jugadores también las respetarán. Pero todo juego construye una narración. Una historia en cuanto que permanece vivo el yo del sujeto actual que juega y puede ganar o perder, que es personaje del relato donde se articula el juego.

En un videojuego el yo y tu, personas, se convierten en jugadores, que asumen el papel de un personaje de la historia sobre la que se construye el videojuego. Ya hemos dicho que el juego, y el videojuego en consecuencia, es un texto; que el texto es virtual; que el videojuego es también un texto narrativo y que la narración en si misma es virtual. Así, pues desde esta perspectiva el videojuego es virtual en cuanto que es texto, en cuanto que es narración y en cuanto que es juego.

Pero el videojuego es también comunicación entre los vidojugadores, jugadores al fin, que luchan entre sí por conseguir un mismo objetivo, o quizá en cooperación con el otro para poder conquistarlo, o, como ya hemos dicho, que juegan consigo mismo o contra una máquina, que es el artilugio para jugar con otro cuando el otro no está, pero que al ser inevitable para poder jugar, su rol lo ejerce un otro mecánico, dotado de aquellas virtualides sin las cuales el jugador no es jugador.

\section{7.-La acción final del juego o la clausura de lo virtual.}

La acción final del juego es la acción final del jugador en cuanto jugador. Cuando el jugador ha conseguido el objetivo, y no olvidemos que el objetivo final de todo jugador es ganar, ya no hay tiempo para más, ni siquiera nuevas opciones. Todas las opciones virtuales que no fueron actualizadas por el jugador o por los jugadores ya no son nada, ni son posibilidades, ni opciones de juego, ni acción de la jugada. Para que el juego vuelva a poseer todo su potencial virtual, es necesario que se reinstaure el juego, que el jugador o jugadores empiecen la partida. Resuelta la primera acción del juego, se abren otras que abren las diversas expectativas de los jugadores. Cada actualización, excepto, la final y definitiva en que se clausura el juego y el relato, abre una nueva posibilidad de jugar. 
Pero el jugador, por decisión del sujeto, de la persona que juega, puede dar por finalizado el juego, abandonarlo o incluso aplazarlo. Entonces nadie ha ganado la partida, la narración se suspende, y no sabremos nunca, quién hubiera ganado, ni cómo se resolverán las acciones de la historia. El abandono del juego es la muerte del relato, la aniquilación semántica de los personajes, el desvarío del sentido. Y sin embargo bastará que otro u otros jugadores vuelvan a jugar para que aparezcan de nuevo todas las expectativas, todas las virtualidades. Y es que el potencial no ha decaido.

\section{8.-El juego después del juego o la conversación entre personas, jugadores y personajes.}

Cuando se acaba el juego, todavía quedan las personas que han jugado con otras, que han representado sus papeles en el relato, que han vivido los personajes por los que han jugado. Y ahora qué. Cuando todo ha terminado queda el sujeto que tiene la experiencia del juego, como jugador y en su caso como personaje. El sujeto guarda la experiencia vicaria como personaje, la experiencia lúdica y virtual como jugador, y la experiencia real como persona que se la juega con otra persona. La pregunta es si quiere seguir jugando. La pregunta es si la memoria que tiene como persona que juega con otros, quiere rescatar algo de lo vivido o proyectar nuevos modos de ser, de relacionarse con otros cuando el juego ha terminado. No cabe la menor duda que el jugar es una experiencia más allá del juego, es una experiencia de mundo, del mundo que genera el juego e instaura el relato, el universo textual. Pero es también una experiencia como sujeto humano que juega con otro. No sólo representa una comunicación, sino que es una comunicación. En este sentido el sujeto que juega con otros ya sea a través de Internet con uno o varios sujetos más, de forma bilateral o multilateral, ya sea un juego entre dos jugadores o entre muchos, o sea un juego de multijugadores, no es un sujeto aislado, se abre primero a un mundo representacional lúdico, y después, puede hacerlo en el espacio del universo real. Todo jugador deja sus huellas en el juego, o sea su estilo de juego; como que deja sus huellas en los medios, con frecuencia también deja su huella en los adversarios, cuya condición misma de adversarios, cesa cuando cesa el juego. Y eso sin citar que existen juegos, que se juegan por parejas, y ahí el adversario es la otra pareja, y el compañero, el cómplice juega a ganar con nosotros. 
Diversos estudios han dejado al descubierto que la relación entre los jugadores no termina con el juego, que luego después, sigue otro tipo de relación, y hasta el punto de que el adversario pueda convertirse en amigo. En todo caso los videojuegos y los videojugadores están aportando una característica más para el universo del ciberespacio.

\section{9.-Ciberespacio y juego o una heterocósmica emergente.}

La memoria es el espacio construido de nuestros mundos, el ámbito donde se ordenan las acciones recordadas, vividas, previstas e inventadas, pero sobre todo las previsibles y proyectadas, aquellas que convertirán en actual lo que fuera virtual; en clausurado, lo abierto.

Los ciberespacios no son sino versiones mecanizadas de los palacios de la memoria renacentistas, construcciones mentales con función de ayuda al recuerdo. (SANCHEZ NAVARRO, J., 2004,25)

La tecnología ha firmado un pacto permanente con una de aquellas potencias del alma. De la memoria, inteligencia y voluntad, ha sido la memoria la elegida. Probablemente ha sido el modelo, ya que la conservación de datos, las relaciones que permiten establecer entre los contenidos y sus elementos formales, y su versatilidad, han sido factores constantes en las tecnologías de la información y la comunicación, que convendría recordar, no son de ayer ni de hoy mismo incluso, sino que aparecen con los primeros soportes donde la piedra ejercita su capacidad versátil de ser dura y grabable, de convertir en memoria la marca, de ser huella comprensible de los signos grabados. La escritura fue ya un sistema de archivo de información; la imprenta, su multiplicación. A mayor número de copias, mas difusión, mayor accesibilidad de los materiales del conocimiento.

Un mundo constituye una totalidad semejante a una red. O es tal vez una red donde se dan las cosas del mundo. Un cosmos es el universo mental creado por las narraciones. Cada narración tiene su mundo y ese mundo es tanto el resultado de la combinación de muchos objetos, escenarios, personajes, espacios, tiempos, acciones, como de la persistencia de una idea a través de la cual se mueve ese mundo, eje sobre el que gira, significado que le da sentido. 
La experiencia que los sujetos del mundo estamos teniendo de nuestras relaciones con el entorno, con los otros sujetos humanos, de nuestras propias vivencias, hoy está transida, transitada y mediada por los medios de la información y la comunicación. No es necesario reclamar la presencia de un ciberespacio. Hay ya una evidencia de que vivimos en una de nuestras versiones actualizadas del poder ser, una virtualidad que cada vez ofrece más salidas para elegir nuestro modo de actualizarnos.

La experiencia que los seres humanos tenemos de las tecnologías que hoy ocupan una parte extensa de nuestro tiempo de trabajo, de nuestras relaciones, de nuestro trabajo, de nuestras horas del día, de nuestros negocios, de nuestras diversiones y, en suma, de nuestra misma cotidianeidad, es cada vez más pregnante. La cibernética es sólo un medio, pero tenemos la sensación de estar inmersos en ella. Y de vivirla como una ideología; la esfera de nuestra existencia pasó a convertirse en iconosfera con la llegada de los medios audiovisuales pero hoy es ya un ciberespacio. Y esa es nuestra visión del mundo. Vivimos este juego y como todo juego, una vez jugado, es irreversible. Y aunque todo juego es susceptible de volver a jugar, como las golondrinas de Bécquer que no volverán, ya será otra experiencia, es más, otro juego, pero no el mismo, en este sentido no se puede volver a vivir lo vivido como no se puede ser el mismo río una vez más como diría Heráclito. Como toda virtualidad, una vez actualizada, ya no tiene vuelta atrás, todas las opciones eran elegibles, pero ya ha hemos elegido. Y esta jugada nos ha dado como resultado el ciberespacio, al menos este ciberespacio. Ya veremos que podemos hacer en la siguiente tirada. Y cómo responderá el contrincante. Los juegos a los que jugamos inventan las historias que vivimos. El texto, no obstante, todavía dice hoy que el hombre es el centro, que la tecnología con que se hace el tiempo y el espacio y se ejecutan las acciones y las relaciones de los hombres es cibernética en gran medida, pero humana. Y que él es el que juega, el que narra, y el protagonista de su vida. Mas por cuánto tiempo? Para que la historia sea nuestra, no podemos olvidar jugar el juego, porque este proviene de las virtualidades de la historia. Lo que pasa es que la materia de la que está hecho el juego alcanza altas proporciones cibernéticas. El ciberespacio ya no es una opción primera, es el espacio sobre el que se juega el juego.

Nuestras relaciones personales amplifican sus posibilidades. Los foros, los blogs, los chats, los emails, los contactos personales por Messenger ofrecen nuevas formas de relaciones personales y grupales en el ámbito más restringido y personal. Y lo hacen ofreciéndonos la posibilidad de relacionarnos a distancia y a tiempo real, a través de escritura, voz e imagen. Los sujetos también eligen una opción de manifestación, 
de activación de sus identidades posibles. Los hombres somos multidentitarios, y ese es nuestro modelo de ser. A través de nuestra vida, del poder ser, se fraguó la realidad de las virtualidades del hombre, cuando seleccionamos una de ellas, nos identificamos como sujetos actuales de comunicación. Incluso cuando nos inventamos otro yo, más que mentir, indagamos en los posibles yoes, fraguamos posibles que no se convirtieron en virtualidades, y que por tanto nunca llegaron a ser realmente actuales. Mentir es otra cosa. Mentir es ir contra las reglas del juego de ser nosotros. Desviarnos de toda lógica. O tal vez sea introducir reglas nuevas sin ser pactadas previamente. Los límites del ser posible, virtual, real y actual se fijan en la coherencia, en no renunciar al jugador que nos hemos hecho. El tiempo y el espacio centran la opción del quién somos ahora actualmente, antes de ser los que fuimos posibles o los que pudimos ser realmente virtuales. El tiempo del yo y el espacio del yo piden la coherencia del yo. El yo como actuante actualiza mi ser. Pero no olvidemos que actualiza una de los posibles. De él soy responsable. El yo individual con sus identidades, resultado de tantas elecciones virtuales. El yo social, más que suma de todos. Y el yo del mundo, inscrito en estos momentos en el espacio-tiempo cibernético. Ya sin retorno, pero abierto de nuevo a múltiples jugadas.

Quien ha jugado tanto a los videojuegos ha construido una forma de ser en el mundo y de ver el mundo. Una forma pregnante. Pero vicaria. Por mucho que se juegue a los videojuegos no será la única forma de vivir el mundo ni vicariamente, ¡hay tantas formas de hacerlo!, ni directamente experiencial. Ahora bien, las estructuras, los mecanismos del juego, del juego en sí, y de los videojuegos particulares con sus reglas explícitas y concretas, irán marcando un modelo de mundo. Sería penoso que frente a las teorías del juego, la narración, del acto de leer, de la experiencia cibernética en general y de los videojuegos en particular que proclaman que lo uno nace de la elección de lo múltiple, se fuera imponiendo, de tanto repetir estructuras de juego simples y groseras, de reducir las opciones más probables a unas pocas jugadas, lo uno sobre lo múltiple. Es un peligro. Pero es más fascinante e inteligente, un ciberespacio en constante expansión creativa.

La expansión del ciberespacio representa la más reciente de las grandes apariciones de objetos inductores de inteligencia colectiva, según Pierre Levy $(1999,11)$ Es un objeto colectivo, dinámico que ha sido y está siendo construido por todos los que lo utilizamos, existe en cuanto que lo usamos, como dice 
Huitema (1995), citado por Pierre Levy, crea un vínculo por el hecho de ser, al mismo tiempo, objeto colectivo de sus productores y de sus exploradores o usuarios.

\section{0.-Conclusión final}

Algunos modelos de juego sirven de inspiración a los videojuegos. Si bien todos los juegos no son narración, la construcción de la inmensa mayoría de los videojuegos remite a la narración, al menos a la formalidad narrativa, al concepto mismo de narración. Ahora bien lo más interesante no son los mundos que puedan compartir videojuegos y relatos, lo más importante es la virtualidad que comparten. Gadamer nos hace reflexionar cuando dice que no es el juego el que hace a los jugadores, sino los jugadores al juego. Esa interactividad intrínseca entre el sujeto que juega y el jugador, esa dialéctica creativa que el videojuego genera en relación con la historia que alimenta, contribuye a una teoría de la narratividad de los juegos. Pero como sólo la narración se crea por las jugadas que efectúan los jugadores, es más cómo sólo la narración se inaugura, avanza y clausura por la acción del juego mismo, y el juego consiste en elegir opciones, según unas reglas, el juego es depósito de la narratividad virtual del juego, la narración es entonces la actualización de la virtualidad que el juego contiene.

\section{Bibliografía.}

CAILLOIS, Roger (1961) Men, Play and Games. Free Press. Nueva York

CANDEIRA, J. (2004) “Apuntes de memoria para una historia personal del ciberespacio” en SANCHEZ NAVARRO, J. (Editor) (2004) Realidad virtual. Visiones sobre el ciberespacio. Devir Contenidos. SL. Barcelona.

HUITÉMA, C. (1995) Et Dieu créa l’Internet. Enrolles. París.

LÉVY, P. (1999) ¿Qué es lo virtual? Paidós Multimedia. Barcelona.

QUEAU, Philippe (1995) Lo virtual. Virtudes y vértigos. Paidos, Cmunicación. Barcelona. 
RYAN, M-L (2004) La narración como realidad virtual. La inmersión y la interactividad en la literatura y en los medios electrónicos. Paidós Comunicación. Barcelona.

SANCHEZ NAVARRO, J. (Editor) (2004) Realidad virtual. Visiones sobre el ciberespacio. Devir Contenidos. SL. Barcelona

SEARLE, John (1969) Speech Acts: An Essay in the Philosphy of Language. Cambridge University Press. (Traducción al Castellano, 1986. Actos de habla. Madrid. Cátedra)

WALTON, K. (1990) Mimesis as Make-Believe: On the Foundations of the Representational Arts. Cambridge, Massachussetts, Harvard University, Press 